\title{
Enhancing Benefits by Rectification in the Absorption Refrigeration Systems
}

\author{
Salek Malaine ${ }^{1 *}$, N. Ababssi ${ }^{1}$, M. Charia ${ }^{2}$, A. Boulal $^{1}$ \\ ${ }^{1}$ Mechanical Engineering, Industrial Management and Innovation Lab (MEIMI Lab), Faculty of Science and Technology, \\ Hassan First University of Settat, Casablanca road, Km 3.5, P.O. Box 577, Settat, Morocco, 26000 \\ ${ }^{2}$ Team of Thermodynamic and Energetic, Faculty of Sciences, Mohammed V University in Rabat, 4 Ibn Battouta street, \\ P.O. Box 1014, Rabat, Morocco, 10000 \\ E-mail: ${ }^{1 *}$ s.malaine@uhp.ac.ma
}

Received 24 April 2021, Revised 07 June 2021, Accepted 17 November 2021

\begin{abstract}
The main objective of this article aims to enhance a single stage absorption refrigeration machine, using the ammoniawater pair as working fluid, and this from the improvement of its exergetic performances by means of a vapor rectification system. The rectifier makes it possible to emit a vapor enriched in pure fluid (ammonia) with a high flow rate; this one is thus transformed into condensate after condensation; as it also allows evacuating a liquid (water) in the form of reflux. Moreover, in order to show the role of the rectifier and to highlight its impact on the operation of the proposed installation, the methodology adopted in this work aims to develop a thermodynamic model of numerical simulation using the FORTRAN language according to two approaches. An energetic analysis approach which aims to assess, in a first time, the performance of the studied refrigeration installation. However, the exergetic approach tries to calculate the exergy efficiency, and thus to evaluate the losses of exergies of the refrigeration installation in a second time. Therefore, the obtained results showed a clear improvement in the exergetic efficiency, accompanied against by an optimization of the losses of exergies which are due to the irreversibility of the studied thermodynamic system. The novelty brought by the present study encourages the engineers and manufacturers to realize the future absorption refrigeration machines integrating rectifier systems.
\end{abstract}

\section{Keywords: Rectifier; simulation model; exergetic efficiency; exergy loss; exergy transfer.}

\section{Introduction}

Absorption refrigeration machines are a hot topic of research today. They arouse growing interest, thanks to their advantages such as the use of low quality heat sources and environmentally friendly working fluid pairs [1]. Among the most used couples in this topic, there are available binary mixtures for these systems, such as lithium bromide-water $\left(\mathrm{LiBr}-\mathrm{H}_{2} \mathrm{O}\right)$ and ammonia-water $\left(\mathrm{NH}_{3}-\mathrm{H}_{2} \mathrm{O}\right)$ [2]. The main problem with $\mathrm{LiBr}-\mathrm{H}_{2} \mathrm{O}$ fluids mixture is the crystallization of the system [3], while the $\mathrm{NH}_{3}-\mathrm{H}_{2} \mathrm{O}$ couple can cause corrosion of the installation. Since, the ammonia has been used as refrigerant in absorption cooling systems for a long time [4]; the choice of the binary ammonia-water solution $\left(\mathrm{H}_{2} \mathrm{O}-\mathrm{NH}_{3}\right)$ as the working fluid of the refrigeration machine [5-6] refer to this mixture presents very interesting characteristics and advantages [7], in particular when attempting to produce cold at temperatures below zero degree Celsius [8-9]. In other words, improving a machine reverts to improving its performances. In this respect, many previous studies and research have been carried out to develop methods of improving the performance of absorption refrigeration systems, in order to make these refrigeration technologies more competitive compared with the conventional compression refrigeration systems [1]. A recently published study by Li Jianbo [10] analyzed and evaluated a new combined absorption-compression refrigeration cycle that can result in waste heat from an internal combustion engine in overloaded vehicles, ships or diesel generators. The results of the theoretical calculation showed that the proposed cycle of the combined absorptioncompression system had a higher coefficient of performance than the compression refrigeration cycle. Two other new hybrid absorption-compression refrigeration systems, using R1234yf/ionic liquid as a mixture of working fluids, have been proposed and analyzed by X. Liu et al [11] in order to improving their performance. For these last two systems, the compressors were placed respectively between the generator and the condenser on one side, and between the absorber and the evaporator on the other side, in order to study the effect of the position of the compressor on the performance of the installations. These studies showed that a greater improvement in COP related to the system with a compressor installed between the absorber and the evaporator. Massamba Thioye [12] exhibited an improvement in the performance of absorption refrigeration machines by the use of staged absorption and desorption cycles consuming energy in the form of heat with low exergetic value. J.Dardouch, M.Charia et al [13] studied energetically, the single absorption refrigeration machine with a distillation column. From this study, it emerges a high performance and optimal operation of the machine in a Moroccan climate. However, the implementation of this installation requires a further study, taking into account the economic aspect based on an exergetic analysis in order to assess the cost of profitability and investment linked to the manufacturing conditions of the refrigeration machine in question. In view of reducing the manufacturing conditions of the absorption refrigeration machine, the installation of a distillation 
column was omitted by the authors M. Ahachad, M. Charia and A. Bernatchou in [14] who carried out a study of the single-stage absorption machine equipped with a bubbling system; and which can act as a distillation stage. Moreover, the study showed that the improved solar refrigeration machine could produce cooling with attractive performance while maintaining the simplicity of the machine. It should be therefore noted that the exergetic analysis was not addressed in this latest study. For this purpose, in thermodynamics, the energetic analysis according to the first law based on the laws of conservation of mass and energy alone remains insufficient to assess the efficiency of such a refrigeration system. Yet, the employment of the second law of thermodynamics, to perform an exergetic analysis of a system is extremely necessary to describe exhaustively qualitatively and quantitatively, the evaluation of the efficiency of this system. In this context, the following question arises:

How can we contribute, through this work, to improving the exergetic efficiency of the refrigeration machine with rectifier, and highlight its repercussion on its irreversibility based on the first and second laws of thermodynamics?

To answer this problem, this work was organized around three axes:

The first axis deals with a description of the proposed refrigeration installation. The second axis presents the thermodynamic analysis procedure, as well as the methodology to be adopted to initiate this study. The third axis describes and interprets the obtained results.

\section{The proposed system design}

The present work concerns the study of performance improvement by a rectification system of a single-stage absorption refrigeration machine illustrated in Figure 1.

\subsection{Absorption frigorific installation without rectifier}

The absorption refrigeration machine is composed of a boiler, a condenser, an evaporator, an absorber, two expansion valves and two heat exchangers. In this frigorific installation, we must distinguish between two circuits:

(a)

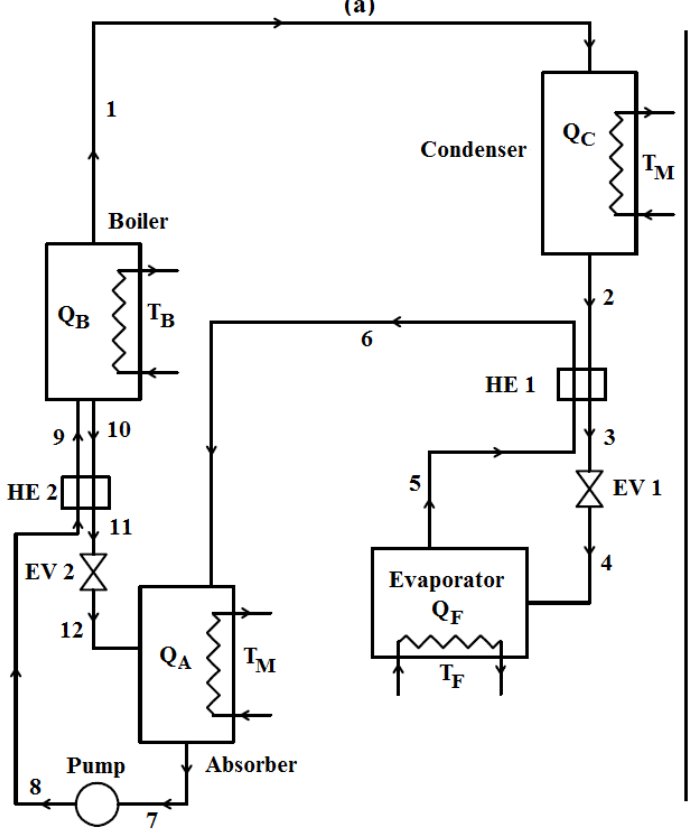

The refrigerant circuit is located between the boiler and the condenser, the evaporator and the absorber, and the circuit of the refrigerant-absorbent solution between the absorber and the boiler (Figure 1 (a)).

Like the compression machine, the absorption machine has low pressure inside the evaporator, and high pressure inside the condenser.

\subsection{Absorption frigorific installation with rectifier}

It is an absorption refrigeration installation, operating with the water-ammonia couple, ammonia is the refrigerant and water is the absorbent [15]. This system is composed of the same elements as the single-stage refrigeration machine, but equipped by rectifier installed at the outlet of the boiler.

In the stationary regime, the operation of the refrigeration installation (Figure 1 (b)) can be summarized as follows:

In the evaporator traversed by a water circuit, the refrigerant (here ammonia) is vaporized in a very low pressure environment. However, the amount of heat from the environment to be cooled at temperature $\mathrm{T}_{\mathrm{F}}$ causes boiling the refrigerant $\left(\mathrm{NH}_{3}\right)$ by extracting heat from this water which is thus cooled. The produced vapors are absorbed by a poor solution in the absorber which contains the absorbent solution at ambient temperature $\mathrm{T}_{\mathrm{M}}$. The rich solution, before entering the boiler, is therefore sent by a pump to supply the rectifier, undergoing heating through the passage by a heat exchanger (HE 2). From the rectifier, a part of water in the form of reflux is routed to the boiler. It receives heat at the temperature $T_{B}$ which causes desorption of the refrigerant. While, the vapor coming out from the boiler reverse, by putting in equilibrating, the rich solution in a rectifier which is located at temperature lower than that of the boiler, and subsequently the vapor leaving from this latter is enriched in ammonia. This system can be considered as a single stage distiller. The impoverished solution is cooled via HE 2 and returns to the absorber through an expansion valve (EV 2). Finally, the vapors leaving the high pressure rectifier are sent to the condenser, and the liquid leaving the latter is thus sent to the evaporator through an expansion valve $(\mathrm{EV} 1)$ undergoing cooling via the passage through a heat exchanger (HE 1) to start again, a new thermodynamic cycle.

(b)

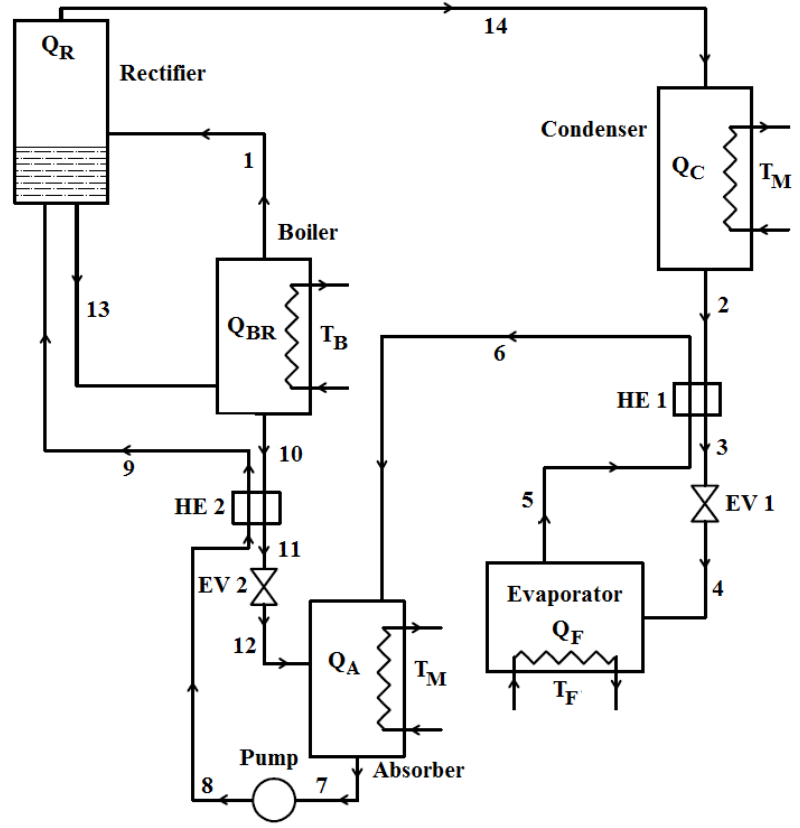

Figure 1. Schematic diagram of a single-stage absorption refrigeration machine: without rectifier (a); with rectifier (b) 


\section{Thermodynamic analysis methodology \\ 3.1 Energetic analysis approach}

According to the first principle of thermodynamics, the energetic analysis of the refrigeration system is based on the establishment of the mass and energy balances of the various elements of the refrigeration machine [16], from the application of the following equations [17]:

$\sum \dot{m}_{\text {in }}=\sum \dot{m}_{\text {out }}$

$\sum_{i} Q_{i}+W=\sum_{\text {out }} \dot{m}_{\text {out }} \cdot h_{\text {out }}-\sum_{\text {in }} \dot{m}_{\text {in }} \cdot h_{\text {in }}$

Table 1.Modeling of mass and energetic balances of the simple absorption refrigeration machine without rectifier.

Components Mass balances; mass concentration; energetic balances

$$
\begin{aligned}
& \dot{m}_{1}+\dot{m}_{10}=\dot{m}_{9} \\
& \dot{m}_{1} \cdot \mathrm{Y}_{1}+\dot{m}_{10} \cdot \mathrm{X}_{10}= \\
& \mathrm{Q}_{\mathrm{B}}=\dot{m}_{1} \mathrm{~h}_{1}+\dot{m}_{10} \mathrm{~h}_{1}
\end{aligned}
$$
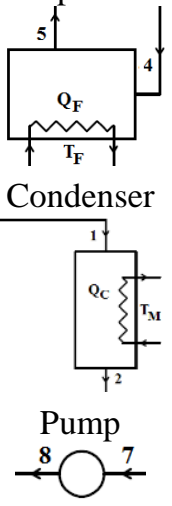$$
\dot{m}_{1} \cdot \mathrm{Y}_{1}+\dot{m}_{10} \cdot \mathrm{X}_{10}=\dot{m}_{9} \cdot \mathrm{X}_{9}
$$$$
\mathrm{Q}_{\mathrm{B}}=\dot{m}_{1} \mathrm{~h}_{1}+\dot{m}_{10} \mathrm{~h}_{10}-\dot{m}_{9} \mathrm{~h}_{9}
$$$$
\dot{m}_{7} \cdot \mathrm{X}_{7}=\dot{m}_{6} \cdot \mathrm{Y}_{6}+\dot{m}_{12} \cdot \mathrm{X}_{12}
$$$$
\mathrm{Q}_{\mathrm{A}}=\dot{m}_{7} \cdot \mathrm{h}_{7}-\dot{m}_{6} \cdot \mathrm{h}_{6}-\dot{m}_{12} \cdot \mathrm{h}_{12}
$$

Expansion valve

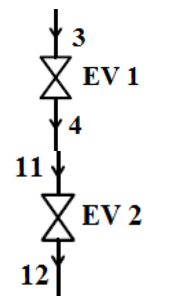

$$
\dot{m}_{3}=\dot{m}_{4}
$$$$
\mathrm{h}_{3}=\mathrm{h}_{4}
$$$$
\dot{m}_{11}=\dot{m}_{12}
$$$$
\mathrm{h}_{11}=\mathrm{h}_{12}
$$

Heat

$$
\begin{array}{ll}
\text { exchanger } & \dot{m}_{2}=\dot{m}_{3} \\
& \dot{m}_{6} \cdot\left(\mathrm{h}_{6}-\mathrm{h}_{5}\right)=\dot{m}_{2} \cdot\left(\mathrm{h}_{2}-\mathrm{h}_{3}\right) \\
& \dot{m}_{8}=\dot{m}_{9} \\
& \dot{m}_{10}=\dot{m}_{11} \\
& \dot{m}_{9} \cdot\left(\mathrm{h}_{9}-\mathrm{h}_{8}\right)=\dot{m}_{10} \cdot\left(\mathrm{h}_{10}-\mathrm{h}_{11}\right)
\end{array}
$$

With: $\dot{m}, \mathrm{Q}_{\mathrm{i}}, W$ and $\mathrm{h}$ represent the mass flow rate $(\mathrm{kg} / \mathrm{sec})$, heat transfer rate $(\mathrm{kW})$, mechanical power $(\mathrm{kW})$ and enthalpy $(\mathrm{kJ} / \mathrm{kg})$, respectively. The abbreviations in and out denote the input and output of the system.

By applying the two equations 1 and 2, the model thus established makes it possible to calculate the quantities of heat exchanged at the level of each component of the refrigeration machine.

Table 1 illustrates the mathematical modeling of the mass and energetic balances of the various components of the simple absorption refrigeration machine without rectifier. The configuration shown in table 1 remains applicable even for the configuration of the machine with rectifier, but with adoption of the new modification shown in table 2 relating to figure 1 (b). Then, table 2 represents the mathematical modeling of the mass and energetic balances of the various components of the refrigeration machine with rectifier.

Table 2. Modeling of mass and energetic balances of the simple absorption refrigeration machine with rectifier.

Components Mass balances; mass concentration; energetic balances
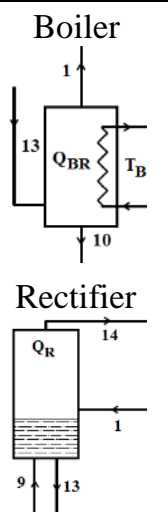

$\dot{m}_{1}+\dot{m}_{10}=\dot{m}_{13}$

$\dot{m}_{1} \cdot \mathrm{Y}_{1}+\dot{m}_{10} \cdot \mathrm{X}_{10}=\dot{m}_{13} \cdot \mathrm{X}_{13}$

$\mathrm{Q}_{\mathrm{BB}}=\dot{m}_{1} \cdot \mathrm{h}_{1}+\dot{m}_{10} \cdot \mathrm{h}_{10}-\dot{m}_{1} \cdot h_{13}(27)$

Condenser

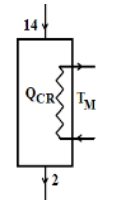

$\dot{m}_{14}=\dot{m}_{2}$

$Q_{C}=\dot{m}_{14 \cdot}\left(h_{2}-h_{14}\right)$

\subsection{Exergetic analysis approach}

\subsubsection{Generality on the exergy concept}

Before performing the exergetic mathematical modeling, it is necessary to define the concept of exergy:

Exergy is the usable part of an amount of energy [18]. It is a quantity allowing to measuring the quality of energy in a system [19-20]. Based on the fundamental principles of this concept [19], the exergy analysis methods help to analyze the irreversibility of a frigorific system [21], with a view to improving these performances by relying on the first and second laws of thermodynamics [22]. They allow energy resources to be used more efficiently [23]. The exergetic analysis is one of the methods applied in various fields of energetic engineering [24], namely cooling and refrigeration to study especially the exergy destroyed [25] in thermodynamic system [26], with a view to minimizing them and maximizing their performance [22]. Nevertheless, the exergy balance describes how much an amount of energy in a process is consumed by it [23].

In this work, the exergy analysis methods to be applied to the machine in a stationary regime, and are dependent on the analysis of the exergy balances on the one hand, and on 
the evaluation of the exergy losses of the various elements of the machine on the other hand. The exergy at any point of a thermodynamic cycle of a refrigerating machine is expressed by the following equation [24, 27-28]:

$\mathrm{E}_{\mathrm{x}}=\dot{m}\left[\left(\mathrm{~h}-\mathrm{h}_{0}\right)-\mathrm{T}_{0}\left(\mathrm{~s}-\mathrm{s}_{0}\right)\right]$

Where:

- $\quad \mathrm{s}$ is the entropy $(\mathrm{kJ} / \mathrm{kg} . \mathrm{K})$.

- $\mathrm{T}_{0}$ is the ambient temperature.

- $\quad h_{0}$ and $s_{0}$ are the enthalpy and the entropy under the standard conditions, respectively.

\subsubsection{Formulation of exergetic balance}

By application of the first and second law of thermodynamics, and based on equation (2) and the entropy balance expressed by the following equation (Eq. (34)):

$\sum_{\text {out }} \dot{m}_{\text {out }} \cdot \mathrm{s}_{\text {out }}=\sum_{\text {in }} \dot{m}_{\text {in }} \cdot \mathrm{s}_{\text {in }}+\sum_{\mathrm{i}} \frac{\mathrm{Q}_{\mathrm{i}}}{\mathrm{T}_{\mathrm{i}}}+\mathcal{P}$

Where $\mathcal{P}$ is the entropy due to the irreversibility of system.

Multiplying Eq. (34) by $\mathrm{T}_{0}$ a makes it possible to write:

$\sum_{\text {out }} \dot{m}_{\text {out }} \cdot \mathrm{T}_{0} \cdot \mathrm{s}_{\text {out }}=\sum_{\text {in }} \dot{m}_{\text {in }} \cdot \mathrm{T}_{0} \cdot \mathrm{s}_{\text {in }}+\sum_{\mathrm{i}} \frac{\mathrm{T}_{0}}{\mathrm{~T}_{\mathrm{i}}} \mathrm{Q}_{\mathrm{i}}+\mathrm{T}_{0} \mathcal{P}$

The system of Eq. (2) and Eq. (35) becomes:

$\sum_{\text {out }} \dot{m}_{\text {out }} \cdot \mathrm{T}_{0} \cdot \mathrm{s}_{\text {out }}+\sum_{\mathrm{i}} \mathrm{Q}_{\mathrm{i}}+\mathrm{W}=\sum_{\text {in }} \dot{m}_{\text {in }} \cdot \mathrm{T}_{0} \cdot \mathrm{s}_{\text {in }}+$

$\sum_{\mathrm{i}} \frac{\mathrm{T}_{0}}{\mathrm{~T}_{\mathrm{i}}} \mathrm{Q}_{\mathrm{i}}+\mathrm{T}_{0} \mathcal{P}+\sum_{\text {out }} \dot{m}_{\text {out }} \cdot \mathrm{h}_{\text {out }}-\sum_{\text {in }} \dot{m}_{\text {in }} \cdot \mathrm{h}_{\mathrm{in}}$

Eq. (36) is equivalent to:

$$
\mathrm{T}_{0} \cdot \mathcal{P}=\left(\sum_{\text {in }} \mathrm{Ex}_{\text {in }}-\sum_{\text {out }} \mathrm{Ex}_{\text {out }}\right)+\sum_{\mathrm{i}} \mathrm{Q}_{\mathrm{i}}\left(1-\frac{\mathrm{T}_{0}}{\mathrm{~T}_{\mathrm{i}}}\right)+\mathrm{W}
$$

With:

- $\mathrm{T}_{0} \cdot \mathcal{P}=\mathrm{Ex}_{1}$ is the exergy loss.

- $\mathrm{Ex}_{\mathrm{in}}, \mathrm{Ex}_{\text {out }}$ represent the exergy at the entry and exit of system, respectively.

We obtain therefore, the fundamental equation designated below Eq. (38), which establishes the exergy balance relating to the refrigeration system.

$\Delta \mathrm{Ex}+\mathcal{P}_{\text {exergie }}=\sum_{\mathrm{i}} \mathrm{Q}_{\mathrm{i}}\left(1-\frac{\mathrm{T}_{0}}{\mathrm{~T}_{\mathrm{i}}}\right)+\mathrm{W}$

It follows that, the second term to perceive adroitly from Eq. (37) represents the irreversibility of the system, thus defined by the following equation [29]:

$\mathrm{I}=\mathrm{E}_{\mathrm{x}_{\mathrm{D}, \mathrm{j}}}=\sum \mathrm{Ex}_{\mathrm{in}}-\sum \mathrm{Ex}_{\mathrm{out}}+\sum\left[\mathrm{Q}\left(1-\frac{\mathrm{T}_{0}}{\mathrm{~T}}\right)\right]_{\mathrm{in}}-\sum[\mathrm{Q}(1-$

$\left.\left.\frac{\mathrm{T}_{0}}{\mathrm{~T}}\right)\right]_{\text {out }}+\sum \mathrm{W}_{\text {in }}-\sum \mathrm{W}_{\text {out }}$

Where $E_{x_{D, j}}$ is the exery destruction for the element $\mathrm{j}(\mathrm{kW})$.

In operation condition, the irreversibility of components of system was significant high when the exergy consumption is reduced [28]. The total exergy destruction (or total irreversibility) of the absorption machine is simply quantified [30] by the sum of exergy destruction in each component [3] and is given by [31]:
$\mathrm{E}_{\mathrm{x}, \mathrm{tot}}=\sum_{\mathrm{j}=1}^{\mathrm{n}} \mathrm{E}_{\mathrm{x}_{\mathrm{D}, \mathrm{j}}}$

With: $\mathrm{n}$ is the number of considered components of system.

Generally, the main objective of the exergetic analysis is to determine the location of exergy losses (affecting the production of system) and the amount of exergy destruction production during the different processes of a thermodynamic cycle [32]. The concept of exergy destruction makes the obtained results by the advanced exergy analysis different well from those obtained by conventional exergy analysis [33]. During the freezing process, the local exergy destruction analysis is performed to quantify the irreversibility produced by energy dissipation and heat transfer [34], and it should be reduced consistently [35].

By applying the last two equations (Eq. (39) and Eq. (40)) and referring to the equation Eq. (37), the total the exergy losses of the system are calculated by the following equation:

$E x_{l, t o t}=Q_{B}\left(1-\frac{T_{0}}{T_{B}}\right)+Q_{F}\left(1-\frac{T_{0}}{T_{F}}\right)+\dot{W}_{P}$

The exergetic efficiency [36] which could express the degree, to which the energy of any component of the system was exploited in quality, is however defined by the following formula:

$\eta_{e x}=\left|\frac{Q_{F}\left(1-\frac{T_{0}}{T_{F}}\right)}{Q_{B}\left(1-\frac{T_{0}}{T_{B}}\right)+\dot{W}_{P}}\right|$

\subsection{Hypotheses}

The energetic and exergetic analysis of the thermodynamic cycle of the absorption machine with and without a rectifier is carried out taking into account the thermodynamic properties of the water-ammonia fluid couple. In order to simplify the theoretical calculations for each component of the refrigeration machine cycle and thus to facilitate modeling, the following assumptions are considered:

- Operation in stationary conditions [40,31].

- The pump is considered isentropic [41].

- Expansion valves are considered isentropic.

- Heat exchangers are considered ideal [42].

- The exergy losses in the heat exchangers are negligible on the side of the heat transfer fluids.

- Kinetic energy and potential energy are negligible $[16,37]$.

\subsection{Methodology}

The simulation model developed in this work is based on establishing the mass, energetic and exergetic balances of the various elements of the single-stage refrigeration machine with and without a rectifier, assumed to be in stationary operating. Firstly, this program allows the determination of the thermodynamic state of physical parameters (pressure, temperature, liquid and vapor phase titer, mass flow rate) at different points of the refrigeration machine cycle. Secondly, the enthalpy at any point of the thermodynamic cycle of refrigerating machines is calculated from the analytical expressions of Gibbs free energy given by B. Ziegler and Ch. Treep $[18,43,44]$ by differentiation method. This makes it possible then, to calculate the quantities of heat exchanged at the level of the various parts of the machine. After that, the 

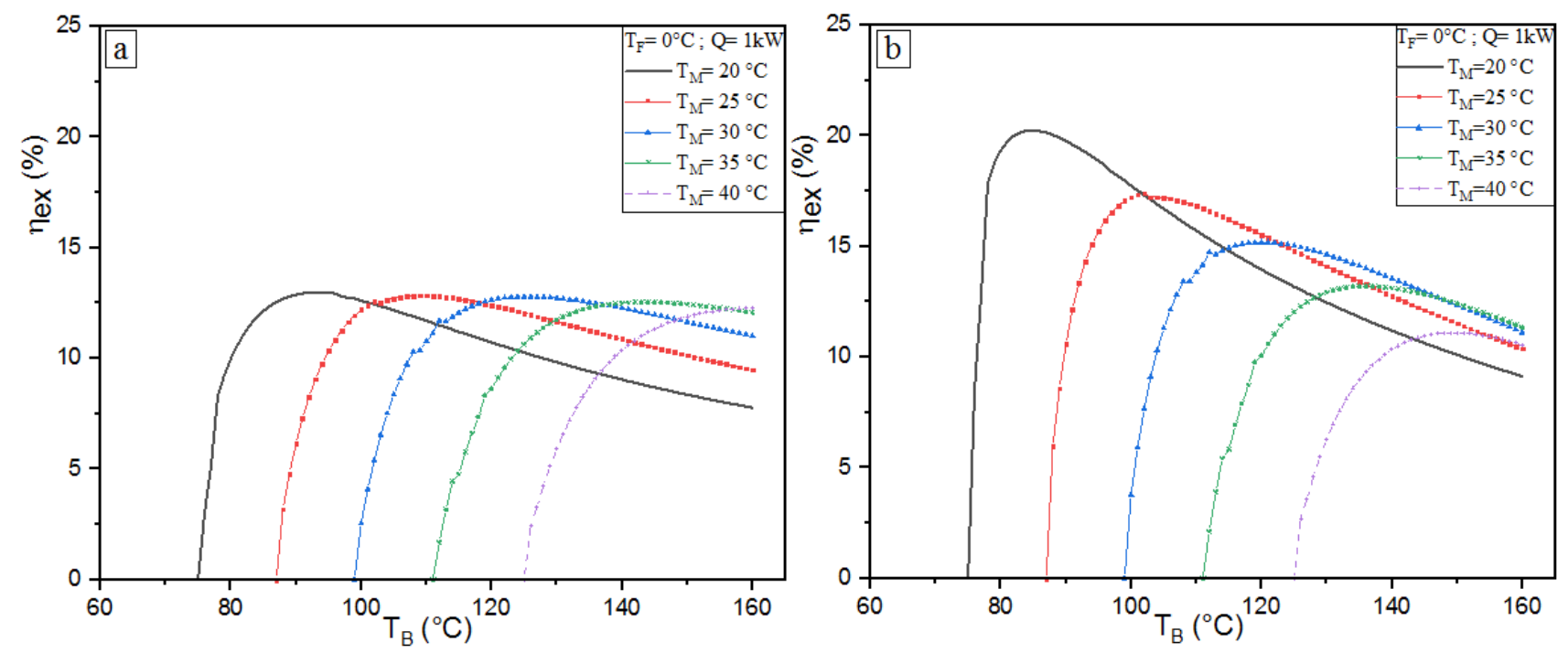

Figure 2. Evolution of the $\eta_{\text {ex }}$ as a function of the temperature of the hot source $T_{B}$ for different values of the average temperature $T_{M}$ of the single-stage refrigeration machine: without rectifier (a); with rectifier $(b)$

established simulation program describes the actual process of the operation of the absorption refrigeration machine. Consequently, the calculation of all other physical quantities is done by using the thermodynamic analysis methods according to the aforementioned energy and exergy approaches.

\section{Results and discussions}

This section details the results of the numerical simulation with a focus on the effect of the rectification process on the exergy efficiency and exergy losses in an absorption refrigeration system.

From different values of the average source temperature $\mathrm{T}_{\mathrm{M}}$, and for an evaporation temperature $\mathrm{T}_{\mathrm{F}}=0^{\circ} \mathrm{C}$ and cooling load $\mathrm{Q}=1 \mathrm{~kW}$, figure 2 illustrates a comparison of the evolution of the exergy efficiency $\eta_{\mathrm{ex}}$ of two types of a single-stage refrigeration machines with rectifier (Figure 2 (b)) and without rectifier (Figure 2 (a)), as a function of the temperature of the hot source $\mathrm{T}_{\mathrm{B}}$. For this two figures, the exergy efficiency $\eta_{\mathrm{ex}}$ reaches its maximum value, respectively, around $12.98 \%$ for the machine without a rectification system and $20.25 \%$ for the machine equipped with a rectifier under the conditions relating to temperatures $\mathrm{T}_{\mathrm{M}}=20^{\circ} \mathrm{C}, \mathrm{T}_{\mathrm{F}}=0{ }^{\circ} \mathrm{C}$. For the other values of $\mathrm{T}_{\mathrm{M}}$, the $\eta_{\mathrm{ex}}$ reaches its minimum values. However, when the temperature $T_{M}$ increases, the exergetic efficiency $\eta_{\text {ex }}$ decreases with the increasing of temperature $\mathrm{T}_{\mathrm{B}}$.

According to these two figures, we have shown that the operating threshold temperatures of machine with and without rectifier decrease when $T_{B}$ decreases with the decreasing in temperature $\mathrm{T}_{\mathrm{M}}$. So, the minimum operating conditions are those which correspond to $\mathrm{T}_{\mathrm{M}}=20^{\circ} \mathrm{C}$.

Figure 3 exhibits an overview on a comparison of the variation of the exergy efficiency $\eta_{\mathrm{ex}}$ of the two studied machines. In this figure, the quality index represented by the parameter $\eta_{\text {ex }}$ of the thermodynamic system is plotted on $y$ axis and the temperature of the hot source $T_{B}$ is plotted on $\mathrm{x}$ axis. We notice that, the two curves in Fig. 3 have almost the same appearance and the same operating temperature with a shift towards the maximum for the representative curve of the machine using rectifier as compared to the not using it. At the temperature $\mathrm{T}_{\mathrm{B}}=85{ }^{\circ} \mathrm{C}$, the maximum exergy efficiency of the absorption refrigerator with rectifier is equal to $20.25 \%$. However, the maximum exergy efficiency of the refrigerator without rectifier is equal to $12.98 \%$ at the temperature $\mathrm{T}_{\mathrm{B}}=93{ }^{\circ} \mathrm{C}$. We have therefore observed an improvement in the exergy efficiency of the refrigeration machine with a rectification system compared to the singlestage frigorific machine. Finally, we obtain a useful gain of exergies around $66 \%$ at $\mathrm{T}_{\mathrm{B}}=85^{\circ} \mathrm{C}$ and about $17.35 \%$ at $\mathrm{T}_{\mathrm{B}}=$ $160{ }^{\circ} \mathrm{C}$ respectively.

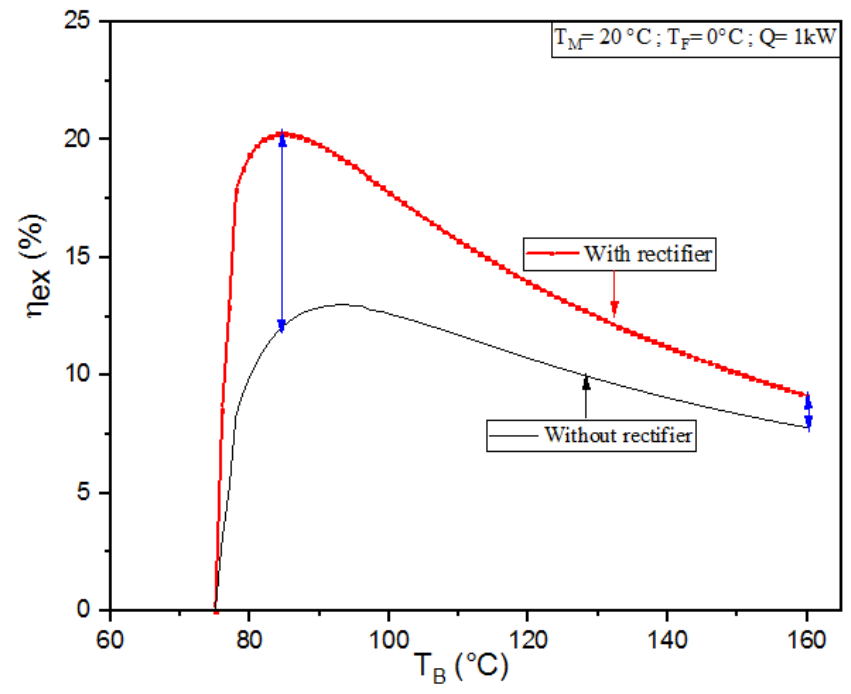

Figure 3. Variation in the exergetic efficiency of the two machines (with and without rectifier).

To evaluate the effect of rectification on the total exergy losses of the thermodynamic system, figure 4 shows the variation in the evolution of the total exergy losses as a function of the temperature of the boiler $\mathrm{T}_{\mathrm{B}}$ and for different values of the temperature of the mean source $T_{M}$. During the evaluation of the total exergy losses relating to the two studied configurations, it appears that these losses of exergies decrease gradually when the temperature of the hot source decreases. We note therefore that the total exergy loss increase with the increasing in the values of the temperature of the mean source for the two studied configurations. From the two representations in figure 4, the minimum exergy losses are obtained for those corresponding to the temperature $\mathrm{T}_{\mathrm{M}}=20^{\circ} \mathrm{C}$. 

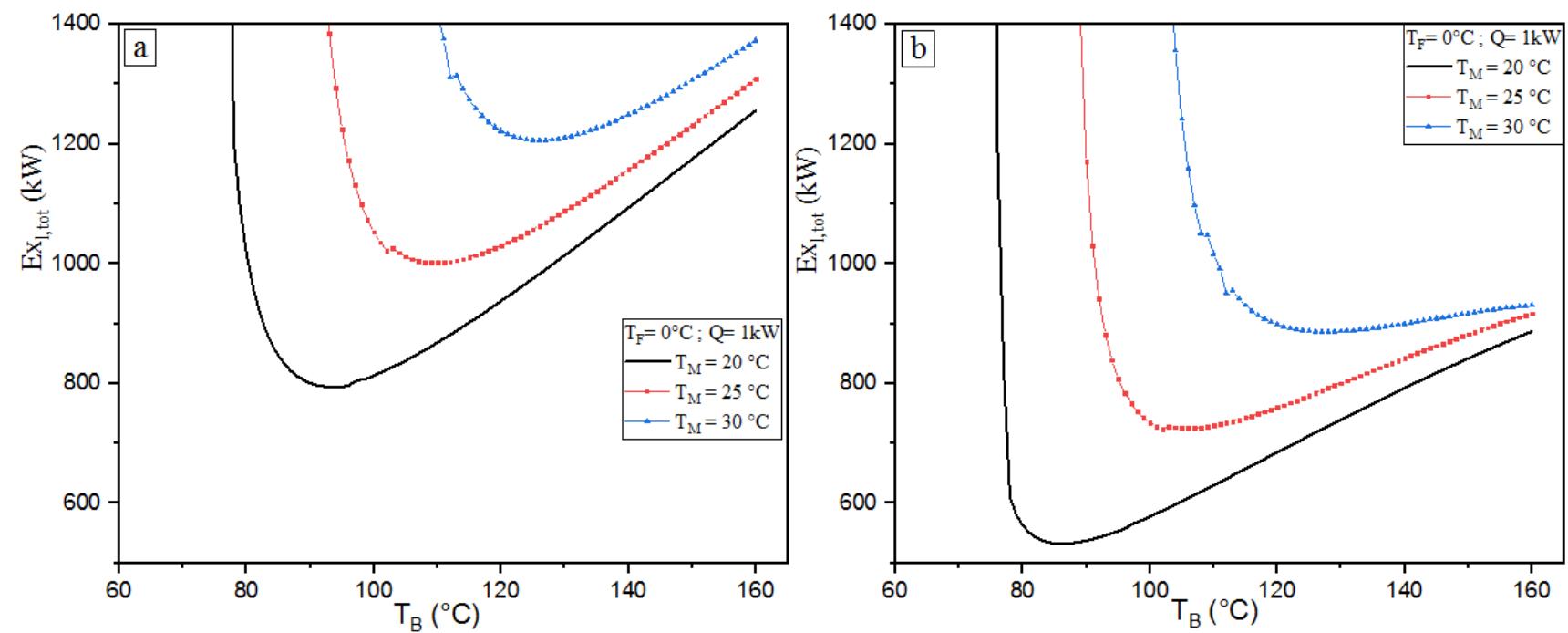

Figure 4. Evolution of the total exergy losses for different values of the average temperature $T_{M}$ of the single-stage refrigeration machine: without rectifier (a); with rectifier (b).

The below Figure 5 highlights a comparison of the variation in the evolution of the total exergy losses, as a function of the temperature of the hot source $\mathrm{T}_{\mathrm{B}}$ for the two absorption refrigeration machines (with and without rectifier). For $\mathrm{T}_{\mathrm{M}}=20^{\circ} \mathrm{C}, \mathrm{T}_{\mathrm{F}}=0^{\circ} \mathrm{C}$ and $\mathrm{Q}=1 \mathrm{~kW}$, we have observed a remarkable reduction in the total exergetic losses produced by the refrigeration machine using the rectifier compared to the single-stage refrigeration machine.

When we fixed the average source temperature $T_{M}$ to 20 ${ }^{\circ} \mathrm{C}$, the total exergy losses of the machine with and without a rectifier have, respectively, a minimum value corresponding to $532.37 \mathrm{~kW}$ at $\mathrm{T}_{\mathrm{B}}=86^{\circ} \mathrm{C}$ and $794.25 \mathrm{~kW}$ at $\mathrm{T}_{\mathrm{B}}=94^{\circ} \mathrm{C}$.

In order to assess how the quantities of exergy losses to optimize evolve, we have chosen the following three points: - For $\mathrm{T}_{\mathrm{B}}=90^{\circ} \mathrm{C}$, we have optimized almost $263.2 \mathrm{~kW}$ of exergy losses.

- For $\mathrm{T}_{\mathrm{B}}=120^{\circ} \mathrm{C}$, the quantity of optimized exergy losses is equal to $252.85 \mathrm{~kW}$.

- For $\mathrm{T}_{\mathrm{B}}=150{ }^{\circ} \mathrm{C}$, the optimized quantity of exergetic losses

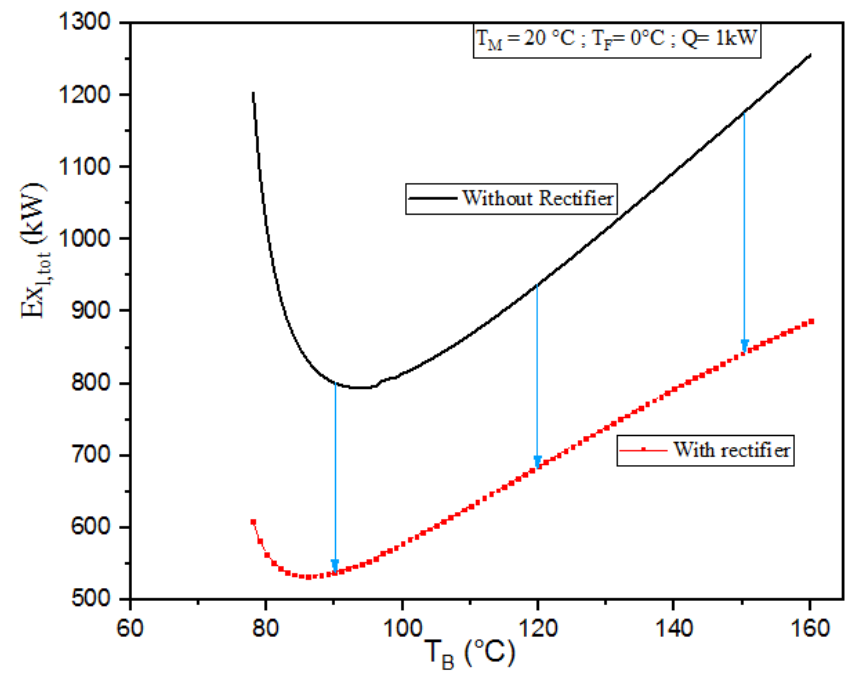

Figure 5. Evolution of the total exergy losses, as a function of the hot source temperature $T_{B}$, for the two configurations of refrigerator. exceeds the $332 \mathrm{~kW}$.

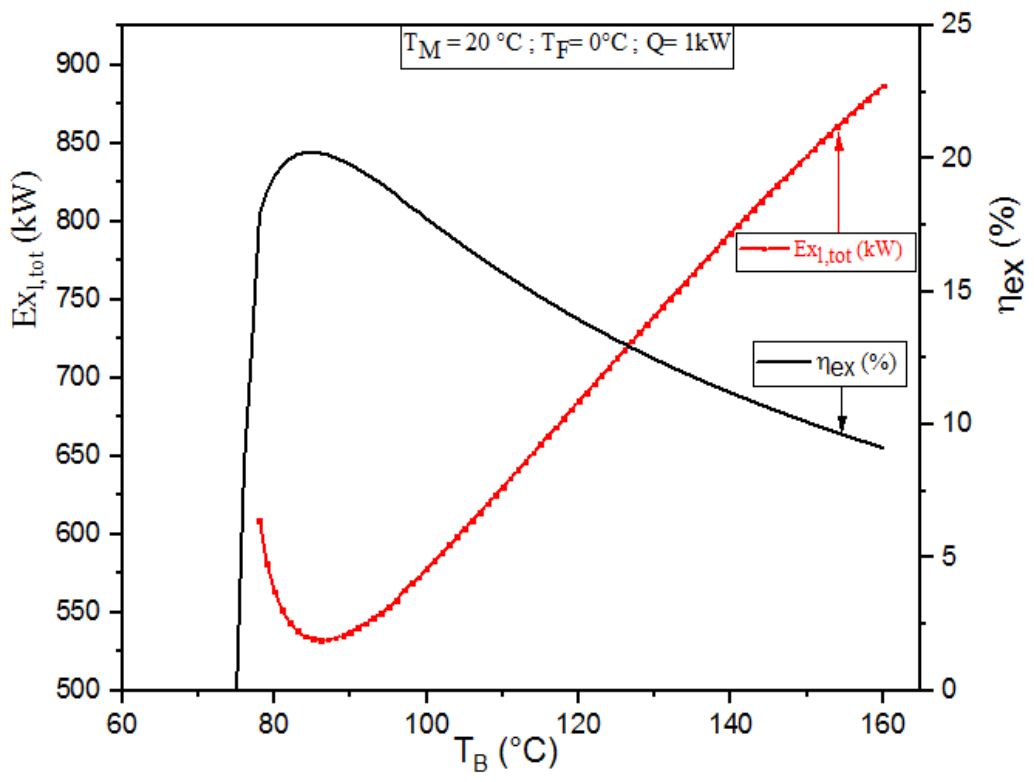

Figure 6. Comparison of the total exergy losses and the exergy efficiency for the refrigeration machine with rectifier. 
This optimization deviation becomes quite large with the increasing temperature of the hot source. We have therefore highlighted the importance of the rectifier and its role in optimizing exergy losses.

In accordance with the objectives previously stated, and in order to demonstrate the relation between the different parameters evaluated in the current study, figure 6 shows the result of a comparison in the variation of the total exergy losses $E x_{1, \text { tot }}$ with the evolution of the exergy efficiency $\eta_{\mathrm{ex}}$ of the refrigeration machine equipped with a rectifier.

According to Figure 6, we notice that when the exergy efficiency reached its maximum, the exergetic losses have becoming minimum. We have therefore observed that the exergy losses evolve in an inversely proportional way, that the exergy efficiency of the absorption refrigerator improved by the rectification system. This means that we have evaluated and verified the reliability of the simulation model established for improving exergy efficiency and optimizing exergy losses of this proposed absorption refrigerator.

\subsection{General interpreting results}

This section deals with a general interpretation of the results obtained by numerical simulation of the chemicalphysics phenomenon of the exergy transfer of matter involved in the absorption refrigeration machine by means of the rectification process.

To close this discussion, the rectifier allows therefore, to promote the exchange of matter and energy (heat) between the gas phase (from the boiler) and the liquid phase (from the absorber), which made it possible to increase the optimum separation power of these two phases within the rectifier. The rectifier allows immediately, as a responsible mechanism to emit the vapors enriched in ammonia with a large flow rate, when they pass through a solution at a temperature below the temperature of the boiler. This ultimately resulted in an increase in the performance of the refrigeration machine, which at the same time caused a significant reduction in these exergy losses.

\section{Conclusion and future recommendations}

The benefit of the improvement provided by the present study lies in maximizing the purification of ammonia as refrigerant by a rectifying mechanism. Through this work, we have demonstrated clearly that the equipment of the refrigeration machine with a rectifier influences in a remarkable manner on its functioning, and therefore on its exergetic performance. The rectifier can reduce the amount of water vapor, emitted by the generator at high temperature, contained in the gas-liquid mixture which is resulting to produce an optimum flowrate of vapor enriched with a pure fluid. The obtained results showed that a considerable reduction in the exergetic losses achieved to minimum values. This is contributing to obtaining simultaneously a significant increase in the performance of the machine with rectifier compared to the simple refrigeration machine.

As a conclusion as expected objective, we succeeded to improve the single-stage refrigeration machine from the improvement of its exergetic efficiency, and consequently the contribution to reduction of the losses of exergies which are due to the irreversibility of the thermodynamic system in question.

The novelty brought by this study encourages the engineers and manufacturers specialists to realize the future absorption frigorific machines integrating rectifier systems.
As future work, we plan to determine and locate the main sources causing the loss of exergies, and searching how to minimize them. As a second step, we will try to carry out a study over the sun of the refrigeration machine with rectifier, based on real solar meteorological data relating to an appropriate Moroccan site.

\section{Nomenclature \\ COP Coefficient of performance \\ EV 1 \& EV 2 Expansion valve number 1 \& 2 \\ HE 1 \& HE 2 Heat exchanger number 1 \& 2 \\ $\mathrm{LiBr}-\mathrm{H} 2 \mathrm{O}$ Lithium bromide-water mixture \\ $\mathrm{NH}_{3}-\mathrm{H}_{2} \mathrm{O}$ Ammonia-Water mixture}

\section{Variables and parameters}

$\begin{array}{ll}\mathrm{E}_{\mathrm{x}} & \text { Exergy flow rate }[\mathrm{kW}] \\ \mathrm{Ex}_{1} & \text { Exergy loss [kW] } \\ \mathrm{Ex}_{\mathrm{l}, \mathrm{tot}} & \text { Total exergy losses [kW] } \\ E_{x_{D, j}} & \text { Exery destruction for element j [kW] } \\ E_{x_{D, t o t}} & \text { Total exegy destruction }[\mathrm{kW}] \\ \mathrm{h} & \text { Specific enthalpy }[\mathrm{kJ} / \mathrm{kg}] \\ \mathrm{I} & \text { Irreversibility [kW] } \\ \dot{m} & \text { The mass flow rate }[\mathrm{kg} / \mathrm{sec}] \\ \mathrm{Q}_{\mathrm{A}} & \text { Heat exchanged by absorber }[\mathrm{kW}] \\ \mathrm{Q}_{\mathrm{B}} & \text { Heat exchanged by the boiler }[\mathrm{kW}] \\ \mathrm{Q}_{\mathrm{BR}} & \text { Heat exchanged by the boiler (case } \\ & \text { rectifier) }[\mathrm{kW}] \\ \mathrm{Q}_{\mathrm{C}} & \text { Heat exchanged by the condenser }[\mathrm{kW}] \\ \mathrm{Q}_{\mathrm{CR}} & \text { Heat exchanged by the condenser } \\ & \text { (case with rectifier) }[\mathrm{kW}] \\ \mathrm{Q}_{\mathrm{e}} & \text { Heat flow exchanged by element e }[\mathrm{kW}] \\ \mathrm{Q}_{\mathrm{F}} & \text { Heat supplied to evaporator }[\mathrm{kW}] \\ \mathrm{Q}_{\mathrm{R}} & \text { Heat exchanged by the rectifier }[\mathrm{kW}] \\ \mathrm{s} & \text { Specific entropy [kJ/(kg.K)] } \\ \mathrm{T} & \left.\text { Temperature [ }{ }^{\circ} \mathrm{C}\right] \\ \mathrm{W} & \text { Mechanical power }[\mathrm{kW}] \\ \dot{W}_{P} & \text { Power pump [kW] } \\ \mathrm{X} & \text { Liquid mass title } \\ \mathrm{Y} & \text { Vapor mass title }\end{array}$

Greek symbols

$\eta_{\mathrm{ex}} \quad$ Exergy efficiency [\%]

$\mathcal{P} \quad$ Entropy due to the irreversibility $[\mathrm{kJ} /(\mathrm{kg} . \mathrm{K})]$

\section{References:}

[1] Rasoul Nikbakhti et al., "Absorption cooling systems Review of various techniques for energy performance enhancement," Alexandria Engineering Journal, 59, 707-738, 2020.

[2] Tuğba Kovacı and Arzu Şencan Şahin, "Energy and exergy analysis of a double-effect $\mathrm{LiBr} \mathrm{H}_{2} \mathrm{O}$ absorption refrigeration system," International Journal of Energy and Environment, Volume 9, Issue 1, pp.37-48, 2018.

[3] Jatin Patel et al., "Exergy Based Analysis of LiCl-H2O Absorption Cooling System," Energy Procedia 109, 261-269, 2017.

[4] Ana CarolinaRosa et al., "Quantitative risk analysis applied to refrigeration's industry using computational modeling," Results in Engineering, Volume 9, 100202, 2021.

[5] Abid Ustaoglu, "Parametric study of absorption refrigeration with vapor compression refrigeration cycle 
using wet, isentropic and azeotropic working fluids: Conventional and advanced exergy approach," Energy, Vol. 201, 117491, 2020.

[6] Sahraoui Kherris et al., "Contribution study of the thermodynamics properties of the ammonia-water mixtures," Thermal Science, Vol. 17, n 3, pp. 891-902, 2013.

[7] João M. Garcia and Armando Rosa, "Theoretical Study of an IntermittentWater-Ammonia Absorption Solar System for Small Power Ice Production," Sustainability, 11 (12), 3346, 2019.

[8] Mohamed Charia et al., "Machine frigorifique à absorption (eau-ammoniac) fonctionnant avec des capteurs plans sur le site de Rabat," Rev. Int. Froid, Vol 14, 297-303, 1991.

[9] Bahram Ghorbani and Mehdi Mehrpooya, "Concentrated solar energy system and cold thermal energy storage (process development and energy analysis)," Sustainable Energy Technologies and Assessments, 37, 100607, 2020.

[10] Li Jianbo et al., "A novel absorption-compression combined refrigeration cycle activated by engine waste heat," Energy Conversion and Management, 205, $112420,2020$.

[11] Xiangyang Liu et al., "Performance comparison of two absorption-compression hybrid refrigeration systems using R1234yf/ionic liquid as working pair," Energy Conversion and Management, 181, 319-330, 2019.

[12] Massamba Thioye, “Amé1ioration de la performance des machines frigorifiques à absorption par l'utilisation de cycles à absorption et désorption étagés," Int J. Ref., Vol. 20, n² 2, pp. 136-145, 1997.

[13] J. Dardouch, M. Charia, A. Bernatchou, A. Dardouch, S. Malaine, F. Jeffali, "Study of solar absorption refrigeration Machine in the Moroccan climate," in (ICMES 2018) Materials Today: Proceeding, 13, 1197-1204, 2019.

[14] M. Ahachad, M. Charia and A. Bernatchou, "study of improved $\mathrm{NH}_{3}-\mathrm{H}_{2} \mathrm{O}$ solar absorption refrigerating machine in Rabat (Morocco)," Solar Energy Materials and Solar Cells, 28, 71-79, (1992).

[15] A. ŞENCAN et al., "Prediction of Liquid and Vapor Enthalpies of Ammonia-water Mixture," Energy Sources, Part A, 33:1463-1473, 2011.

[16] Gurjeet Singh, P. J. Singh, V. V. Tyagi, P. Barnwal and A. K. Pandey, "Exergy and thermoeconomic analysis of cream pasteurisation plant," Journal of Thermal Analysis and Calorimetry (Springer), 137 (4), 1381-1400, 2019.

[17] MA Javadi et al., "Optimization and analysis of exergy, economic, and environmental of a combined cycle power plant," ãdhanã , 44 (5), 1-11, 2019.

[18] Charia Mohamed. (1990). Contribution à l'étude des machines frigorifiques à absorption mono-étagées et biétagées (Doctoral dissertation), FSR, Mohammed V in Rabat University.

[19] Silvio de Oliveira Junior, Exergy: Production Cost and Renewability, $1^{s t} E d$. Springer Science \& Business Media,
2013.

[20] V. Vikul and S. D. Raja, "Experimenta and Exergy Analysis of Ammonia/Water Absorption System using Ethylene Glycol [C2H4(OH)2] in the Evaporator," Energy Procedia, 109, 401-408, 2017.

[21] Peizhe Cui et al., "Energy, exergy, and economic (3E) analyses and multi-objective optimization of a cascade absorption refrigeration system for low-grade waste heat recovery," Energy Conversion and Management, 184, 249261, 2019.

[22] Ayad Khudhair Al-Nadawi, "Irreversibility Analysis of R407C, R404A, and R134A as an Alternatives of R22 in Vapor Compression Chiller under Cycling Conditions," International Journal of Thermodynamics, Vol. 24, $\mathrm{n}^{\circ} 1$, pp. 24-29, 2021.

[23] Sandro Nizetic, Agis Papadopoulos, The Role of Exergy in Energy and the Environment, $1^{s t} E d$. Springer International Publishing, 2018.

[24] Rupp Carriveau et al., "Transient thermodynamic modeling of an underwater compressed air energy storage plant: Conventional versus advanced exergy analysis," Sustainable Energy Technologies and Assessments 31 (2019) 146-154.

[25] Thamer Khalif Salem, Saad Sami Farhan, Israa Sami Farhan, "Energy and exergy analysis study of heat exchanger in a refrigeration system with different lengths of capillary tube," International Journal of Thermodynamics, 23 (4), 260-266, 2020.

[26] Anarghya Ananda Murthy et al., "A review on expanders and their performance in vapour compression refrigeration systems," International Journal of Refrigeration 106, 427-446, 2019.

[27] Huawei Wu et al., "Heat transfer analysis of energy and exergy improvement in water-tube boiler in steam generation process," Journal of Thermal Analysis and Calorimetry, 139 (4), 2791-2799, 2020.

[28] Zhihua Wang et al., "Exergy analysis of a frost-free air source heat pump system," Journal of Mechanical Science and Technology, 33 (5), 2439-2450, 2019.

[29] N. D. Shikalgar, S.N. Sapali, "Energy and exergy analysis of a domestic refrigerator: approaching a sustainable refrigerator," Journal of Thermal Engineering, Vol. 5, n 5, pp. 469-481, 2019.

[30] Michel Wakim and Rodrigo Rivera-Tinoco, "Absorption heat transformers: Sensitivity study to answer existing discrepancies," Renewable Energy, 130, 881-890, 2019.

[31] Muhammad Umer Arshad et al., "Thermodynamic analysis and optimization of double effect absorption refrigeration system using genetic algorithm," Energy Conversion and Management, 192, 292-307, 2019.

[32] Hamed Kariman et al., "Energetic and exergetic analysis of evaporation desalination system integrated with mechanical vapor recompression circulation," Case Studies in Thermal Engineering, Vol. 16, 100548, 2019. 
[33] Yuan Zhang et al., "Exergy destruction analysis of a low-temperature Compressed Carbon dioxide Energy Storage system based on conventional and advanced exergy methods," Applied Thermal Engineering, Vol. $185,116421,2021$.

[34] Nelson O. Moraga and Diego R. Rivera, “Advantages in predicting conjugate freezing of meat in a domestic freezer by CFD with turbulence k- $\varepsilon$ 3D model and a local exergy destruction analysis," Int. Jour. of Refr., doi.org/10.1016/j.ijrefrig.2021.02.002.

[35] Chinedu F. Okwose, Muhammad Abid, Tahir A.H. Ratlamwala., "Performance analysis of compressorassisted two-stage triple effect absorption refrigeration cycle for power and cooling," Energy Conversion and Management., Energy Conversion and Management, 227 , 113547, 2021

[36] Ramen Kanti De and Aritra Ganguly., "Energy, Exergy and Economic Analysis of a Solar Hybrid Power System Integrated Double-E®ect Vapor Absorption SystemBased Cold Storage," International Journal of AirConditioning and Refrigeration, Vol. 27, n 21950018 (13 pages), 2019.

[37] Boris Huirem and Pradeepta Kumar Sahoo, "Thermodynamic Modeling and Performance Optimization of a Solar-Assisted Vapor Absorption Refrigeration System (SAVARS)," International Journal of Air-Conditioning and Refrigeration, Vol. 28, $\mathrm{n}^{\circ} 1,2050006$ (18 pages), 2020.

[38] Xiao Zhang et al., "Energetic and Exergetic Investigations of Hybrid Configurations in an Absorption Refrigeration Chiller by Aspen Plus," Processes, 7 (9), 609, 2019.
[39] Wei Wu et al., "Comparative analysis of conventional and low-GWP refrigerants with ionic liquid used for compression-assisted absorption cooling cycles," Applied Thermal Engineering, 172, 115145, 2020.

[40] Manel Vallès, M Bourouis, D Boer, "Solar-driven absorption cycle for space heating and cooling," Applied Thermal Engineering, Vol. 168, 114836, 2020.

[41] XuPing et al., "Prediction and optimization of isentropic efficiency of vortex pump under full operating conditions in Organic Rankine Cycle waste heat recovery system based on deep learning and intelligent algorithm," Sustainable Energy Technologies and Assessments., Vol. 42, , 100898, December 2020.

[42] Ahmad Fakheri, "Heat Exchanger Efficiency," Journal of heat transfer, 129 (9):1268-1276 (9 pages), 2007, https://doi.org/10.1115/1.2739620.

[43] B. Ziegler and Ch. Trepp, "Equation of state for ammonia-water mixtures," Int. Jour. Of Ref., Vol. 7, ${ }^{\circ}$ 2, Pages 101-106, March 1984.

[44] VijayChauhan et al., "Thermodynamic analysis of a combined cycle for cold storage and power generation using geothermal heat source," Thermal Science and Engineering Progress, Volume 11, Pages 19-27, June 2019. 